\title{
R E L A T O S
}

\section{LA REVISTA «ARQUITECTURA» (1918-1936) LOS DÍAS CONTADOS DE LA MODERNIDAD}

\author{
Delfín Rodríguez \\ Profesor de Literatura de la Universidad de Salamanca
}

$\mathrm{M}$

odestamente, con un ropaje sobrio y austero, empieza hoy la Sociedad Central de Arquitectos á publicar una revista». De este modo, claro y conciso, se abrían, en 1918, las Palabras Iniciales de una de las revistas más importantes de la cultura arquitectónica y artística en la España del siglo Xx. Arquitectura, aún hoy viva, nacía con la intención de contar los días de lo arquitectónico o, al menos, de contarlo casi todo, lo que constituye, a la vez, su mayor atractivo y, según algunos historiadores de la modernidad y la vanguardia en España, su mayor debilidad. Porque, en efecto, sus páginas no narran exclusivamente una historia de éxito, la de lo moderno, la de la vanguardia, fácil de contar y llena de recursos dramáticos, sino que pretende hablar diversas lenguas, como en desorden, como el mismo transcurrir de los días, atenta tanto a la memoria del pasado y de la tradición como a las nuevas propuestas del Movimiento Moderno, muchas de ellas contradictorias entre sí.

No fue, por tanto, Arquitectura, entre 1918 y 1936, una revista de tendencia o de vanguardia, pero tampoco fue una publicación de resistencia ante lo moderno o simplemente ecléctica, como tiende a considerarla la historiografía canónica de lo moderno que ha llegado a expulsarla de sus más recientes taxonomías. Desde su fundación, desde las Palabras Iniciales recordadas, la redacción de la revista Arquitectura revelaba que los arquitectos eran conscientes de estar viviendo una época decisiva y contradictoria que era necesario asumir: «debemos contemplar con amor la obra realizada y la que comienza: el pasado, con todo su atractivo sentimental, y el porvenir, cuajado de esperanzas.» Una época que entendían como el inicio de lo nuevo y, al tiempo, como el espacio de confrontación y de tensión entre «dos concepciones distintas». Por eso, en sus páginas, a través de proyectos y textos, fotografías y dibujos, se encierran reflexiones de carácter histórico, ensayos sobre los nuevos instrumentos conceptuales de restauración arquitectónica, atención a problemas de construcción derivados del uso de nuevas técnicas y materiales, junto a noticias y artículos de nuevos edificios tantos europeos o norteamericanos como españoles, noticias y divulgación de las diferentes posiciones de lo moderno en la arquitectura europea y norteamericana, de las vanguardias neoplásticas al racionalismo o al funcionalismo, incluidas las fructíferas meditaciones sobre las relaciones entre lo popular y la van- 
guardia, entre la tradición y lo moderno, que casi dan el tono final de la revista. Un tono de una modernidad pulcra, algunos dirían que vigilada por la tradición, que afectó no sólo a la arquitectura proyectada y construida en esos años en España, sino también al arte de la época. Así lo entendieron, además, los dos principales responsables de la revista en este período, Leopoldo Torres Balbás y José Moreno Villa, dos nombres fundamentales de la cultura española en este momento, a los que debería unirse la inusitada y estimulante actividad del arquitecto Fernando García Mercadal.

Melancolías y promesas de futuro, tradición y mecanización del mundo y de la arquitectura, historia y sueños, el habitar en el mundo contemporáneo, en el correr de los días, se convertían en los argumentos que la nueva revista estaba decidida a analizar en su trayectoria. Pero contar los días no era tarea fácil, casi implicaba la aspiración a contarlo todo. Por sus páginas pasaron, ya fuera escribiendo o siendo reproducidos sus proyectos y construcciones, los principales arquitectos y activistas de las vanguardias arquitectónicas europeas, de Theo van Doesburg y Bruno Taut a W. Gropius, L. Mies van der Rohe o Le Corbusier, de Robert Mallet-Stevens o Paul Linder a A. Perret, Hannes Meyer o H. Tessenow, además, como es lógico, de arquitectos españoles como Teodoro de Anasagasti, Secundino Zuazo, Fernando García Mercadal, Luis Blanco Soler, Rafael Bergamín, Luis Gutiérrez Soto, Luis Lacasa, Luis Feduchi o Carlos Arniches, por sólo citar algunos.

156 También los artistas, pintores y escultores, ocuparon un lugar en las páginas de Arquitectura, especialmente los artistas de los arquitectos, de Mateo Hernández a J. Capuz, de Manolo Hugué a Perez Mateo, de Diego de Rivera o Luis Quintanilla a Angel Ferrant, Gargallo o Alfonso Olivares. Es decir, todo un termómetro para medir las temperaturas oscilantes del proyecto de modernización de España, incluidas meditaciones sobre el problema de la vivienda y de la ciudad, del habitar en lo moderno.

Y esta es la historia narrada en la magnífica exposición que puede contemplarse en la Fundación Cultural del Colegio Oficial de Arquitectos de Madrid, organizada en colaboración con el Ministerio de Fomento, y comisariada por Carlos de San Antonio. Una historia poliédrica e híbrida, mezclada y babélica, difícil de contar y, sin embargo, extraordinariamente clara. 